\title{
Inserting new concepts into a traditional arts school: The University of Art and Design Cluj-Napoca, Romania
}

\author{
Andrei Budescu \\ University of Art and Design \\ Cluj-Napoca Romania \\ Piata Unirii 31, 400098 \\ andrei.budescu@uad.ro
}

\author{
Diana Drăgan-Chirilă \\ University of Art and Design \\ Cluj-Napoca Romania \\ Piata Unirii 31, 400098 \\ diana.dc@gmail.com
}

\author{
Oana Gui \\ University of Art and Design \\ Cluj-Napoca Romania \\ Piata Unirii 31, 400098 \\ oana.gui@uad.ro
}

\begin{abstract}
The paper presents the University of Art and Design Cluj-Napoca Romania, emphasizing the challenges posed by the introduction of contemporary technology in art within a traditional art institute and also some aspects that surfaced after a survey of the educational background of the candidates and students, which revealed some worrying tendencies related to the level of understanding of our contemporary high technology and its pervasive influence, not only in our country, but also worldwide.
\end{abstract}

Digital Culture. Digital Art. Digital Humanities. Curricula Development

\section{INTRODUCTION}

Over the past 10 years, Cluj-Napoca has become an important IT hub in Romania. IT and higher education became the main driving forces of the economy of a city that once went through the "forced industrialisation era" of the former communist regime. Nevertheless, after the 1989 Revolution, art has regained its identity in the city with art centres like The Paint Brush Factory, The Centre of Interest and The Cluj Cultural Centre [Turner, Z., 2013].

The University of Art and Design Cluj-Napoca Romania (UAD), founded in 1926, has been in the spotlight of contemporary art world since alumni artists and curators such as Adrian Ghenie, Ciprian Mureșan, Serban Savu, Victor Manor Mihai Pop (Plan B Gallery) became internationally acclaimed [Gotthard, 2017].

The paper presents some surprising results of a survey related to the profile of the candidates and students of our art university, together with the efforts done to insert some new concepts in our traditional arts university. Besides some particular aspects which are strictly related to the national educational system, the survey captured some worrying tendencies related to the level of understanding of our contemporary high technology and its pervasive influence, which are of great concern in many countries], not only in Romania [Carr, N, 2008; Foer, 2017, Newman, 2017].
As artists preoccupied with the role of art in society, at this particular point in our societal paradigm [Bowen, Giannini 2017], we try to emphasize some clear-cut questions which are often obscured in the present society, where,

“... we shop with Amazon; socialize on Facebook; turn to Apple for entertainment; and rely on Google for information" [Foer, 2017].

As artists and also as educators, can we do something to avoid living in a world divided between those who use technology and those who understand it, as depicted in Figure 1?

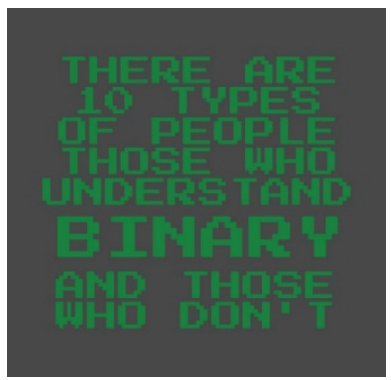

Figure 1: What type do we want to belong to?

\section{THE UNIVERSITY OF ART AND DESIGN}

Forced to adopt the social realism for 50 years during the communist regime, UAD was able to return, after 1989, to international standards in art 
higher education. UAD is now part of the European Higher Education Area (EHEA), has a strong Erasmus+ Programme and provides high education in the field of arts through the ECTS Bologna system. Though UAD is trying to align more and more to the contemporary standards in higher education, the conservative national educational system slows down all developing processes.

UAD has two faculties: Fine Arts (Painting, Sculpture, Graphics, Conservation-Restoration, Photo-Video and Image Processing, Art History) and Decorative Arts and Design (Design, Ceramicglass-metal, Textile Arts, Fashion Design).

All traditional art departments have an important place in the UAD, in accordance with art history, while the Photo-Video and Image Processing Department of the UAD is comparatively new, and bears the burden of launching a new art and technology movement in our university. The new visual and interactive art concepts within this department pose challenges, ranging from helping those in other departments understand the connection between art and technology and how collaboration works in the new environment, up to the huge bureaucracy imposed by the National Ministry of Education associated with the chronic underfinancing of the cultural field.

\subsection{Particular aspects of the education system in Romania}

Education in Romania is based on a free-tuition, egalitarian system, regulated and enforced by the Ministry of National Education. The school educational cycle ends in the twelfth grade, when students graduate the baccalaureate. Higher education is aligned onto the European Higher Education Area. A compulsory condition for admission to any university is to hold a valid baccalaureate.

There are different types of high-school free to offer one or more academic programs: theoretical programs (sciences, including informatics, or humanities), technical programs, vocational programs and services and economics programs. The vocational program is the only one which provides art education in Romania.

As already mentioned, the only compulsory condition for the admission at any university is a valid baccalaureate diploma, which means there is no restriction related to the graduated academic program. Universities are free to organise their admission exams, according to their own criteria.

Admission at UAD is based on three different criteria. First, the artistic skills of the students are tested by a unique test, a 5 hours drawing session in charcoal or pencil, usually a portrait/double portrait/ with/without hands, test graded as admitted/rejected. The admitted candidates are further tested on specific artistic skills, according to the department they have chosen and the last test takes the form of an interview with a presentation of a portfolio. After such a severe admission exam, one would expect that only high school graduates from vocational schools would attend the admission. Yet, the results of the survey about graduates and students were rather surprising, with $31,5 \%$ of the candidates having a different background from the expected vocational one.

Table 1: Comparison between curricula from different types of Romanian high schools (extracted from the official curricula)

\begin{tabular}{|c|c|c|}
\hline Curricula & Vocational Art High Schools & Sciences High Schools \\
\hline General competencies & $\begin{array}{l}\text { Development of contemporary user } \\
\text { skills; } \\
\text { Knowing how to use some IT } \\
\text { products. }\end{array}$ & $\begin{array}{l}\text { Identifying the data specific to a problem and applying } \\
\text { the basic algorithms of processing them; } \\
\text { Development of problem solving algorithms; } \\
\text { Implementation of algorithms in a programming } \\
\text { language (usually C++). }\end{array}$ \\
\hline Values and attitudes & $\begin{array}{l}\text {...forming the ability to use IT } \\
\text { products }\end{array}$ & $\begin{array}{l}\text {..expressing a creative thinking in structuring and } \\
\text { solving problems; } \\
\text {...forming the habit of resorting to specific algorithmic } \\
\text { concepts and methods in addressing a variety of } \\
\text { problems. }\end{array}$ \\
\hline Content & $\begin{array}{l}\text { Word } \\
\text { Excel } \\
\text { Power Point } \\
\text { Access }\end{array}$ & $\begin{array}{l}\text { Oriented and non-oriented graphs; } \\
\text { Dynamically allocated data structures; } \\
\text { Tree like data structures; } \\
\text { Programming methods: greedy algorithm, backtracking, } \\
\text { divide et impera, dynamic programming; } \\
\text { Analysis of the efficiency of algorithms; } \\
\text { Pointers, references, dynamic memory allocation; }\end{array}$ \\
\hline Allocated time & 1 hour a week & 7 hours a week \\
\hline
\end{tabular}




\subsection{UAD survey of candidates and students}

After finding a surprisingly high percentage of the candidates, $31,5 \%$, having a different background from the expected vocational one, another unexpected result was the even higher percentage of admitted students, $43 \%$, coming from high schools different from the vocational ones. Keeping in mind that the vocational program is the only one that involves art studies, and also the fact that the admission is focussed on the artistic skills, the only plausible interpretation is that those students used their free time and resources to gain the much needed skills and competencies. This is a remarkable result that indicates also their determination in following a career path. The high number of students with a different background ended up almost evenly distributed in four of the UAD departments, at parity with students who studied art in high school: Photo, Video, Image processing, Design and Textile and Fashion Design. This $50 \%-50 \%$ distribution determined us to draw a comparison between the level of IT knowledge studied during high school, results which are depicted in Table 1 (extracts from the official site of the National Education Ministry, curricula for the 2017-2018 academic year). A very interesting picture emerged: while students coming from art high schools are trained to become just "users" of technology, those coming from science high schools are trained to "express a creative thinking in structuring and solving problems... forming the habit to resort to specific algorithmic concepts...".

It is an amazing result, which clearly indicates that the division of society in those who use technology and those who understand it has its roots in our own educational system. Obscured in the many pages of the curricula provided by the National Ministry of Education is a crystal clear conclusion: some are trained to be IT users, some are trained to have a creative thinking and advanced knowledge in IT. Alas, it is a clear indication of how "umbrella terms", such as "computer literacy" most often hide real problems that should be addressed properly.

\subsection{Introducing new concepts}

Having to work with such heterogeneous group of students is a major obstacle for the teachers from the Photo, Video, Image processing Department, which need a longer time and special skills to bring the students to a common level of knowledge. Another obstacle facing the need to adapt the curricula to such a fast changing domain is the overloading of the students with subjects studied in traditional arts universities, such as UAD. Good examples are the Anatomy and Compared Anatomy, studied for two of the three years of the B.Sc., at a level close to that of a medicine university. Due to a huge bureaucracy, it takes more than a year to introduce a new subject on the curricula. In order to avoid this delay, many new, interdisciplinary subjects are offered as alternative, optional courses. But this adds to an already overloaded program.

The creative process of the digital artistic work implies a strong cooperation between the artist and a team of programmers, engineers, designers. Digital art has produced works that wipe the borders between disciplines - art, science, technology - and has its roots in different subjects including that of research labs and academies. From this perspective, Cluj benefits from the presence of some of the best universities in Romania, from the climate of cooperation and the exchange of ideas between scholars and researchers.

Despite of the communist isolation, the Stuttgart Impulse Computerart itinerant exhibition was presented by Herbert W. Franke at the Goethe Institute in Bucharest in 1974. The same year painter Florian Maxa, who later became full professor at UAD, presented a computer graphics work at a collective exhibition in Bucharest, followed, in 1976 by a computer graphics exhibition. But art based on digital principles and technologies has been in the making since '60-'70 also behind the Iron Curtain, in Romania, Hungary or the former Yugoslavia. One of the most representative Romanian artists in this field is Sherban Epuré, who pioneered the use of science, algorithms and geometry in art since 1968. Active in his native Romania until 1980, year when the PCs were under embargo there "for undermining the national industry", he emigrated to the US, adding to a long line of Romanian artists, like Constantin Brâncuși, Victor Brauner or Tristan Tzara, who found recognition abroad.

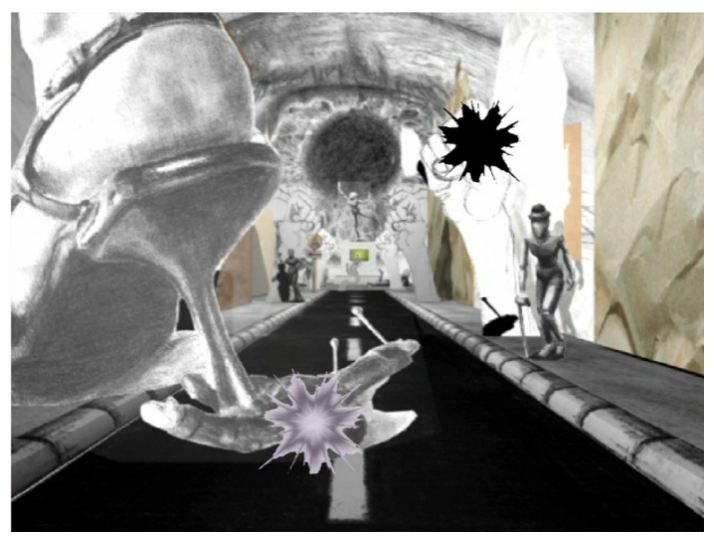

Figure 2: Multimedia animation, author: Flaviu Haitonic 
Since the last decade of the $20^{\text {th }}$ century multimedia and computer based animation courses were introduced at our university, too. The artistic education combines forms of expressions rooted in tradition and cultural heritage but also the freedom given by innovation. Research on animation as a transit state between traditional and digital graphics has thus the chance of exceptional amplification both from a conceptual and an applicative and interdisciplinary point of view.

The omnipresence of the visuality in today's communication offers us opportunity for modeling and practicing the relationship between tradition, the archaic and innovation, reform, revision and experiment. Computer based animation can use insertions from other territories of art in the modeling of its path, most important of all the territory of drawing / graphic sign. So with the help of animation along with extensions of other traditional artistic forms (most importantly painting) and new, innovative forms like the art of photography, video art, digital art and the art of the virtual world the proposal to innovate the artistic experiment can excel in tendencies, attempts and results, as shown in Figure 2.

Manifestation of interdisciplinarity as a concept but also a technical approach is present in our extended offer of art courses. Working with students we use technical support not only as a tool but also as a way of expressing a message through digital medium. As an example of using the video image as a medium not just as a technical tool, we present in Figure 3 a still image from one of our student's video-performance work

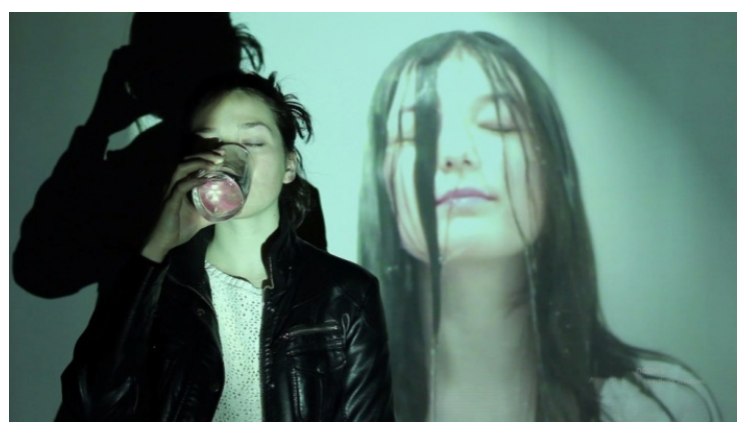

Figure 3: Video performance, author: Adina Antoce

\section{CONCLUSIONS}

Creativity and technology are two key generation differentiators of young people (Net-gen, Z-gen...). Yet, paradoxically, more and more young people limit themselves to be just passive users of technology and have no idea what is "under the hood", giving access to every facet of their identities and influence over every corner of their decision making to corporate giants.
Current curricula (both high school and university) could be a major factor leading to this unwanted situation. But how can we turn students from simply users to creative coders and digital artists? Without a minimum understanding of the technologies involved, how can we be sure that digital art is not simply determined by its technologies and has no social or cultural meaning?

What is needed is an education system fit for the $21^{\text {st }}$ century. Easy task for a system that is under perpetual reform, changing 20 ministers of education in 30 years... But to remain optimistic, let's remember that a Romanian was a central character in the Dada movement (Tristan Tzara) and another Romanian is the creator of The Theatre of the Absurd (Eugène lonesco).

\section{REFERENCES}

Bowen, J.P., Giannini, T., Polmeer, G. (2017). Coded Communication: Digital senses and Aestetics, Merging Art and Life. In: Bowen, J. P, Diprose, G., Lambert, N. (eds.), Proceedings of Electronic Visualisation and the Arts (EVA 2017) London, UK, 11 13 July 2017. BCS, Electronic Workshops in Computing, pp. 1 - 5. DOI: 10.14236/ewic/Eva2017.1

Carr, N. (2008). Is Google Making Us Stoopid? What Internet is doing to our brains, The Atlantic, https://www.theatlantic.com/magazine/archive/2008 /07/is-google-making-us-stupid/306868/ (last accessed on 14.06.2018).

Foer, F. (2017). World Without Mind: The Existential Threat of Big Tech, Penguin Press, New York.

Giannini, T., Bowen, J. P. (2017). Life in Code and Digits: When Shannon met Turing. In: Bowen, J. P, Diprose, G., Lambert, N. (eds.), Proceedings of Electronic Visualisation and the Arts (EVA 2017) London, UK, 11 - 13 July 2017. BCS, Electronic Workshops in Computing, pp.51-57. DOI: 10.14236/ewic/Eva2017.1

Gotthardt, A. These 15 Galleries Are Putting New Cities on the Art World's Map,

https://www.artsy.net/article/artsy-editorial-15galleries-putting-new-cities-art-worlds-map (last accessed on 14.06.2018).

Newman, G. (2017). How might Generative Art be a Proposition for Cross Curricular Learning in Schools. In: Bowen, J. P, Diprose, G., Lambert, N. (eds.), Proceedings of Electronic Visualisation and the Arts (EVA 2017) London, UK, 11 - 13 July 2017. BCS, Electronic Workshops in Computing, pp. 121 - 125. DOI: 10.14236/ewic/Eva2017.29

Paul, C. (2003). Digital Art, Thames\&Hudson, New York.

Turner, Z. A Medieval Romanian City with Major Art Talent, 2013:

https://tmagazine.blogs.nytimes.com/2013/11/12/ar t-matters-a-medieval-romanian-city-with-major-arttalent/(last accessed on 14.06.2018). 